\title{
EDITORIAL
}

\section{EXPANDING OUR VISION}

\author{
JAMES WINTERSTEIN, D.C., D.A.C.B.R., F.I.C.C.
}

Submit inquiries and gallery proofs to: James Winterstein, D.C., D.A.C.B.R., F.I.C.C. President, National University of Health Sciences, 200 E. Roosevelt Road,Lombard, IL 60148,630-889-6604, jwinterstein@nuhs.edu

National University has a reputation of leading in the chiropractic profession and that leadership is exemplified in part by the fact that it was National in 1978 who began to publish the first and still the only scientific journal in the chiropractic profession included in Index Medicus. The Journal of Manipulative and Physiological Therapeutics (JMPT) has become known worldwide as the scientific mouthpiece of the chiropractic profession.

Today, we, National University of Health Sciences, in conjunction with the Council on Diagnosis and Internal Disorders of the American Chiropractic Association and the American Academy of Chiropractic Physicians are initiating a new journal called the Journal of Chiropractic Medicine.

Doubtless there will be heartburn over the title, but it was chosen to represent a profession that needs to become thoroughly modern, integrated and science/ evidence based. It is intended to be a journal that will expand the boundaries of the profession by expanding its ideas, its vision, and its willingness to escape the chains of past dogma.

The term "chiropractic medicine" is completely appropriate and meaningful for it recognizes the reality of the English language as it exists. Medicine, by definition means (From the Oxford Dictionary) (1):

\begin{abstract}
"That department of knowledge and practice which is concerned with the cure, alleviation and prevention of disease in human beings, and with the restoration and preservation of health. Also, in a more restricted sense, applied to that branch of this department which is the province of the physician, in the modern application of the term; the art of restoring and preserving the health of human beings by the administration of remedial substances and the regulation of diet, habits, and the conditions of life."
\end{abstract}

Medicine, it its true meaning, consists of those things doctors do to help other humans gain and maintain health and prevent disease. As the Paradigm of the Association of Chiropractic Colleges (2) clearly states, it is our purpose as doctors of chiropractic to "optimize health."

The word "medicine" should not give members of our profession any difficulty. On the contrary, its use in conjunction with the word "chiropractic" makes good grammatical sense and good definitional sense. It also causes others to begin to use the term "allopathic medicine" when that form of healing is referenced, or "osteopathic medicine," or "homeopathic medicine," or "naturopathic medicine," as the case may be. It was with these realities in mind that we chose the name of this new Journal, which is intended to provide a peerreviewed forum for publication of papers on the practice of chiropractic medicine, especially as it relates to primary care.

As a president of a chiropractic college and now a university with a chiropractic program, I have participated in many meetings of the profession, the Association of Chiropractic Colleges, the Council on Chiropractic Education (CCE) and many others and I have always been dismayed by the propensity of some of our members to insist upon imposing personal dogma into our rhetoric, our planning processes, our Standards of Education, our Standards of Licensure and on and on. We are well known for making up definitions that suit our dogma.

A classic example of this kind of thinking has been the talk of "chiropractic primary care," which was advanced time and time again in the CCE as a proposal for the Forward to the Standards (3). What, in this great society, is "chiropractic primary care?" The meaning is known only to those who have made up the term. The rest of our society understands certain things when the phrase "primary care" is used.

It is not as if this issue has not been around for a long time. I served on a Comprehensive Health Planning (CHP) panel in the late seventies. It was clear even then that our health care matrix was being divided up by government forces into 3 components:

1. Primary care.

2. Secondary care.

3. Tertiary care. 
Since that time, in a general sense, all of the health care world except the chiropractic world has functioned within these parameters. Primary care has several accepted components as clearly described by the Institute of Medicine as follows:

"Primary care is the provision of integrated, accessible health care services by clinicians who are accountable for addressing a large majority of personal health care needs, developing a sustained partnership with patients and practicing in the context of family and community" (4).

I can envision no good reason why a small profession that encounters somewhere around $10 \%$ of the population should feel it is appropriate to attempt to develop a definition of its own that is different from that which is iterated above. Who would care? To the contrary, it is our responsibility as a licensed profession to mold and shape our professional practices to fit and indeed fill the needs of society. Inasmuch as we have been educated to properly diagnose and treat humans with their myriad illnesses, it is now time for us to get into the primary care harness and offer humanity that which we are able to provide-namely, competent diagnostic skills and broad-scope natural healing. Within these parameters, I have no doubt that chiropractic physicians can provide competent primary care as defined by the Institute of Medicine.

\section{REFERENCES}

1. The Compact Oxford English Dictionary. Second Edition. Oxford, England; Clarendon Press; 1989:1056.

2. The ACC Chiropractic Paradigm, Position Paper \#1, Association of Chiropractic Colleges, July 1996.

3. The Council on Chiropractic Education Commission on Accreditation. Standards for Accreditation of Doctor of Chiropractic Programs and Institutions. Scottsdale, AR: February 2001:V.

4. Donaldson M, Yordy K, Vanselow N. Defining Primary Care: An Interim Report, Institute of Medicine. Washington, DC; National Academy Press; 1994:1. 